BMJ Open

Sport \&

Exercise

Medicine

\title{
Influence of muscle fibre composition on muscle oxygenation during maximal running
}

\author{
Tomoharu Kitada, Shuichi Machida, Hisashi Naito
}

To cite: Kitada T, Machida S, Naito $\mathrm{H}$. Influence of muscle fibre composition on muscle oxygenation during maximal running. BMJ Open Sport Exerc Med 2015;1:e000062. doi:10.1136/bmjsem-2015000062

- Prepublication history for this paper is available online. To view these files please visit the journal online (http://dx.doi.org/10.1136/ bmjsem-2015-000062).

Accepted 28 October 2015

CrossMark

Graduate School of Health and Sports Science, Juntendo University, Inzai-shi, Chiba, Japan

Correspondence to Dr Hisashi Naito; hnaitou@juntendo.ac.jp

\section{ABSTRACT}

Aims: To investigate the relationship between muscle oxygenation (specifically, the levels of oxygenated haemoglobin and myoglobin [0xyHb/Mb]) during maximal running and muscle fibre composition, and to determine whether muscle fibre composition can be non-invasively estimated from $0 x y \mathrm{Hb} / \mathrm{Mb}$ levels during maximal running.

Methods: Eight male runners $\left(\dot{\mathrm{V}} \mathrm{O}_{2 \max }, 60.9_{ \pm}\right.$ $4.6 \mathrm{~mL} \cdot \mathrm{kg}^{-1} \cdot \mathrm{min}^{-1}$ ) performed an incremental running test on a treadmill. $0 x y \mathrm{Hb} / \mathrm{Mb}$ levels of the vastus lateralis during maximal running were measured by near-infrared spectroscopy (NIRS). Muscle fibre composition of the vastus lateralis was determined from muscle biopsy samples from the same region measured by NIRS, and the fibre types were classified as type I, type Ila, or type IIb fibres using traditional $\mathrm{pH}$-sensitive ATPase staining. Type I and type Ila fibres together were defined as oxidative fibres.

Results: $0 x y H b / M b$ levels during running were lowest at exhaustion in all participants. $0 x y H b / M b$ levels at exhaustion were positively correlated with the percentages of type I fibres $(r=0.755, p<0.05)$ and oxidative fibres $(r=0.944, p<0.01)$.

Conclusions: We conclude that higher $0 x y \mathrm{Hb} / \mathrm{Mb}$ levels at exhaustion during maximal running are correlated with a higher percentage of oxidative fibres, indicating the potential importance of oxidative fibres in the maintenance of $0 x \mathrm{Hb} / \mathrm{Mb}$ levels during maximal running. Additionally, muscle fibre composition could be non-invasively estimated from oxyHb/Mb levels during maximal running tests in runners.

\section{INTRODUCTION}

Near-infrared spectroscopy (NIRS) is a noninvasive method for measuring oxygenated and deoxygenated forms of haemoglobin ( $\mathrm{Hb})$ and myoglobin $(\mathrm{Mb})$ within the microvasculature; it can be used to evaluate muscle oxygenation in local tissue. ${ }^{2}$ Typically, the level of oxygenated $\mathrm{Hb}$ and $\mathrm{Mb}$ (oxyHb/ $\mathrm{Mb})$ is influenced by blood flow; it decreases when the $\mathrm{O}_{2}$ supply is lower than $\mathrm{O}_{2}$ consumption, for example, during high-intensity exercise. Furthermore, the oxyHb/Mb level decreases when muscle activity and lactate

\section{What are the new findings?}

Muscle fibre composition of the vastus lateralis may be non-invasively estimated from the minimum levels of oxygenated haemoglobin and myoglobin in this muscle during a maximal incremental running test.

accumulation increase in response to exercise intensity, suggesting that increasing exercise intensity involves the recruitment of organised fast-twitch fibres and enhanced $\mathrm{O}_{2}$ dissociation following lactic acidosis. ${ }^{3-5}$ If slow-twitch oxidative (type I) fibres and fast-twitch oxidative glycolytic (type IIa) fibres are superior to fast-twitch glycolytic (type IIb) fibres in terms of $\mathrm{O}_{2}$ supply capacity, and if fast-glycolytic fibres lead to decreased oxy $\mathrm{Hb} / \mathrm{Mb}$ levels, changes in oxy $\mathrm{Hb} / \mathrm{Mb}$ levels may be influenced by muscle fibre composition. However, the relationship between oxyHb/Mb levels and muscle fibre composition remains unclear.

To the best of our knowledge, NIRS studies investigating the direct relationship between muscle oxygenation and muscle fibre composition have been limited to repeated isometric plantarflexion exercises at submaximal intensity. ${ }^{6}$ However, in order to apply the findings of such research to a competitive sport, that is, to improve sports performance, it is important to investigate this relationship during dynamic exercises, such as running at maximal intensity. In addition, while the gastrocnemius was targeted in the previous study, ${ }^{6}$ muscle biopsy sampling from the vastus lateralis is typically used for evaluating sport aptitude.

We hypothesised that muscle fibre composition of the vastus lateralis may be correlated with oxyHb/Mb levels; thus, the present study aimed to establish a new method for the non-invasive evaluation of sport aptitude by estimating muscle fibre composition from oxyHb/Mb levels. Accordingly, we 
investigated the relationship between oxyHb/Mb levels during maximal running and muscle fibre composition and examined whether muscle fibre composition of the vastus lateralis could be non-invasively estimated from the oxyHb/Mb levels. We further hypothesised that a higher percentage of oxidative fibres would lead to a greater potential to maintain oxyHb/Mb levels.

\section{METHODS}

Subjects

Eight college-age male middle-distance runners participated in this study (table 1). Prior to participation, all participants were informed of the potential risks and discomforts associated with the experiment, and all participants provided written informed consent. This study was conducted in accordance with the Declaration of Helsinki and was approved by the Ethics Committee of Juntendo University.

\section{Maximal incremental running test}

All participants performed an incremental running test on a treadmill. After a 3 min rest in a standing position, the run was initiated at $9 \mathrm{~km} / \mathrm{h}$ for $3 \mathrm{~min}$, followed by an increase in speed of $1 \mathrm{~km} / \mathrm{h}$ per min until exhaustion. During the test, respiratory gas-exchange values were measured using an Aeromonitor (AE-300S; Minato Medical Science, Japan) to determine $\mathrm{O}_{2}$ uptake $\left(\dot{\mathrm{V}}_{2}\right)$, and maximal $\mathrm{O}_{2}$ uptake $\left(\dot{\mathrm{V}}_{2 \text { max }}\right)$ was determined as the highest $30 \mathrm{~s}$ average $\dot{\mathrm{V}} \mathrm{O}_{2}$ value. ECG monitoring (DS-7210, Fukuda Denshi, Japan) was continuously performed during the running test.

\section{Muscle oxygenation}

A portable continuous wave NIRS device (Pocket NIRS Duo; Hamamatsu Photonics KK, Japan), consisting of a main unit and two probes, was used to measure oxygenation of the vastus lateralis during the incremental running test. Only one of the two probes was used for all measurements. The measured data were transmitted to a personal computer via a wireless system. ${ }^{7}$ The principles of the measurement have been fully described

Table 1 Physical and physiological characteristics of the participants $(n=8)$

\begin{tabular}{|c|c|}
\hline Characteristic & Mean \pm SD \\
\hline Age, years & $20.0 \pm 1.2$ \\
\hline Height, cm & $173.4 \pm 7.1$ \\
\hline Weight, kg & $61.3 \pm 5.5$ \\
\hline Lean body mass, kg & $54.4 \pm 5.9$ \\
\hline Fat, \% & $11.4 \pm 3.0$ \\
\hline Skinfold thickness of vastus lateralis, $\mathrm{mm}$ & $3.1 \pm 0.6$ \\
\hline$\dot{\mathrm{V}} \mathrm{O}_{2 \max }, \mathrm{mL} \cdot \mathrm{kg}^{-1} \cdot \mathrm{min}^{-1}$ & $60.9 \pm 4.6$ \\
\hline Type I fibres, \% & $37.5 \pm 6.2$ \\
\hline Type Ila fibres, \% & $45.2 \pm 3.1$ \\
\hline Type Ilb fibres, \% & $17.4 \pm 4.4$ \\
\hline
\end{tabular}

elsewhere. ${ }^{1}$ Light-emitting diodes of three different wavelengths $(735,810$ and $850 \mathrm{~nm})$ were used in the probe, which was moulded in elastic black silicone rubber. Based on the modified Beer-Lambert law, ${ }^{8}$ concentration changes in oxygenated $\mathrm{Hb}$ and $\mathrm{Mb}$ (oxyHb/ $\mathrm{Mb})$, deoxygenated $\mathrm{Hb}$ and $\mathrm{Mb}(\operatorname{deoxy} \mathrm{Hb} / \mathrm{Mb})$, and the sum of these two (total $\mathrm{Hb} / \mathrm{Mb}$ ), were calculated by transforming these wavelengths and were expressed in arbitrary units (AU). The optrode separation distance was $3 \mathrm{~cm}$, corresponding to a penetration depth of approximately $1.5 \mathrm{~cm} .{ }^{59}$ Changes in the NIRS signal are reported as $\mathrm{Hb} / \mathrm{Mb}$ because the signal does not distinguish between $\mathrm{Hb}$ and $\mathrm{Mb}$.

The probe was secured on the skin surface with a customised seal, covered by polychloroprene boarding to prevent contamination from ambient light, and secured with elastic tape (Multipore, 3M Japan, Japan) to prevent downward sliding without restricting the range of motion or blood flow during the running test. The probe was placed on the skin over the left vastus lateralis muscle, $15 \mathrm{~cm}$ from the knee, parallel to the major axis of the thigh, and $3-5 \mathrm{~cm}$ outward from the thigh. In order to determine the characteristics of the muscle region, ultrasonography (SSD-900; Hitachi Aloka Medical, Japan) was used to observe the elevated portion of the muscle belly and to simultaneously measure the skinfold thickness. NIRS parameters are influenced by the light path length. ${ }^{2}{ }^{10}$ Therefore, to enable a comparison between participants, the value was quantified by correcting for vastus lateralis skinfold thickness using the formula described by Niwayama, et al. ${ }^{11}$ While participants were at rest in the supine position for approximately $30 \mathrm{~min}$, NIRS signals were monitored on a personal computer until a steady state was established, at which time the signal was set at 'zero'. Then, NIRS signals were measured during running until exhaustion. NIRS data were sampled at $10 \mathrm{~Hz}$.

\section{Muscle fibre composition}

A muscle biopsy sample was taken with a $14 \mathrm{G} \times 75 \mathrm{~mm}$ needle (ONECUT; TSK Laboratory, Japan) from the left vastus lateralis at the same region that was measured by NIRS on a different day. After uniform orientation of the muscle fibre bundle in embedding medium (OCT compound; Tissue-Tek, Sakura Finetek USA, Inc, USA) under a stereomicroscope, the muscle sample was immediately frozen with liquid nitrogen and stored at $-80^{\circ} \mathrm{C}$. Transverse sections $\left(10 \mu \mathrm{m}\right.$ thick) were obtained at $-20^{\circ} \mathrm{C}$ using cryostat (LEICA CM3050S; Leica Biosystems Nussloch GmbH, Germany). After preincubations at $\mathrm{pH}$ 4.3 and 4.61, the muscle samples were stained according to the ATPase method to determine muscle fibre composition; ${ }^{12}$ fibres were classified as type I, type IIa and type IIb. The type I and type IIa fibres together were defined as oxidative fibres. For each participant, approximately 200 fibres were assessed by a computerised planimetry system and each fibre type was expressed as a percentage of the total number counted. 


\section{Statistical analysis}

Statistical analysis was performed for all the NIRS parameters (SPSS Statistics for Windows, V.17.0; SPSS Inc, Chicago, Illinois, USA). Data are presented as mean \pm SD. The relationship between muscle fibre composition and oxyHb/Mb level was analysed using Pearson's correlation coefficient. Statistical significance was set at $\mathrm{p}<0.05$.

\section{RESULTS}

$\dot{\mathrm{V}} \mathrm{O}_{2 \max }$ during the incremental running test was 60.9 $\pm 4.6 \mathrm{~mL} / \mathrm{kg}$ per min. Figure 1 shows the changes in $\mathrm{oxyHb} / \mathrm{Mb}$ levels of the vastus lateralis from supine rest (zero) to exhaustion in all participants during the incremental running test. The oxyHb/Mb level decreased with exercise intensity (running speed) and reached a minimum value $(-0.383 \pm 0.061 \mathrm{AU})$ at exhaustion in all participants. Similarly, deoxyHb/Mb levels increased with exercise intensity and reached a maximum value $(0.433 \pm 0.091 \mathrm{AU})$ at exhaustion, and total $\mathrm{Hb} / \mathrm{Mb}$ at exhaustion was $0.049 \pm 0.107 \mathrm{AU}$. The mean percentages of type I, type IIa and type IIb fibres in the vastus lateralis from all participants were $37.5 \pm 6.2 \%, 45.2 \pm 3.1 \%$ and $17.4 \pm 4.4 \%$, respectively. The percentage of type I fibres $(\mathrm{r}=0.755, \quad \mathrm{p}<0.05$; figure $2 \mathrm{~A})$ and oxidative fibres $(\mathrm{r}=0.944, \mathrm{p}<0.01$; figure $2 \mathrm{~B})$ was positively correlated with the minimum $0 x y \mathrm{Hb} / \mathrm{Mb}$ level of the vastus lateralis. The percentages of type I fibres $\left(\mathrm{Y}_{1}\right)$ and oxidative fibres $\left(\mathrm{Y}_{2}\right)$ obtained from oxyHb/Mb levels $(\mathrm{X})$ during maximal running were expressed as the following linear regression equation: $\mathrm{Y}_{1}=76.702 \times \mathrm{X}-66.864\left(\mathrm{r}^{2}=0.57\right)$ and $\mathrm{Y}_{2}=68.256 \times-108.79\left(\mathrm{r}^{2}=0.89\right)$, respectively.

\section{DISCUSSION}

In this study, we investigated the relationship between oxyHb/Mb levels during maximal running and muscle fibre composition, using NIRS and muscle biopsy from the vastus lateralis muscle. We found a significant correlation between minimum oxyHb/Mb levels during



Figure 1 Changes in the levels of oxygenated haemoglobin and myoglobin (oxyHb/Mb) of the vastus lateralis from supine rest (zero) to exhaustion in all participants during the incremental running test $(n=8)$. The data plot legend (right) indicates the percentages of oxidative (types I and Ila) fibres of each participant.
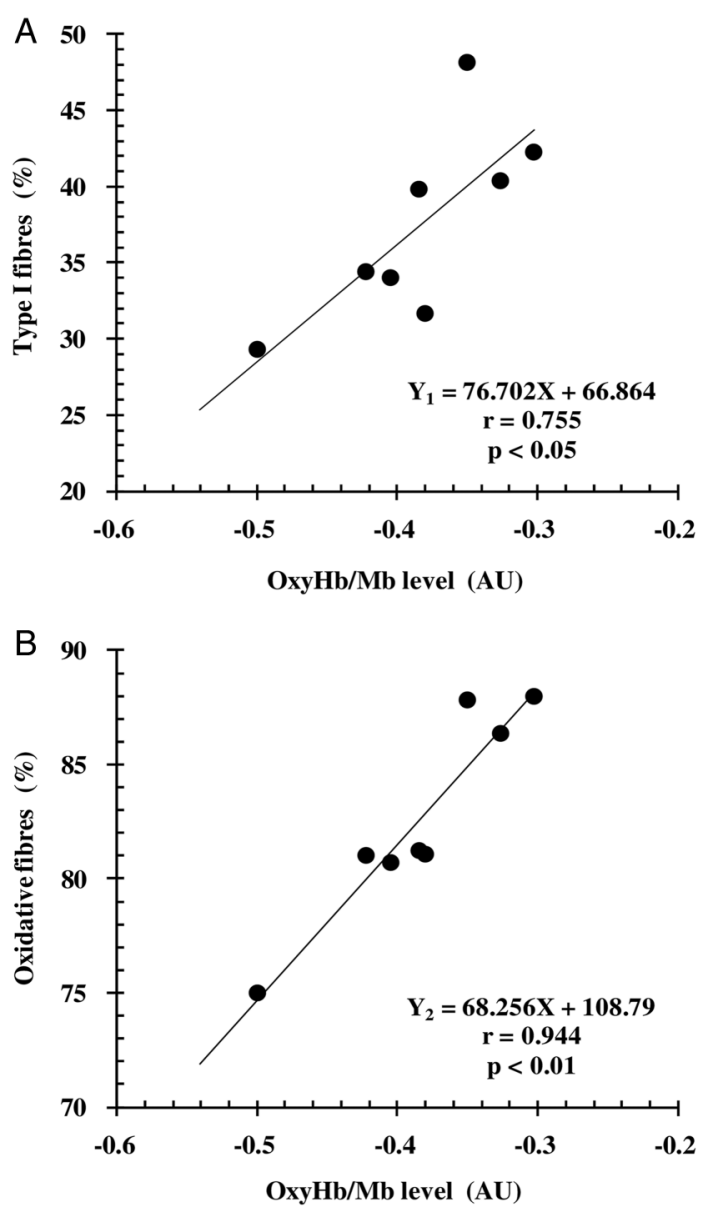

Figure 2 Relationship between minimum levels of oxygenated haemoglobin and myoglobin (oxyHb/Mb) of the vastus lateralis during maximal running $(X)$ and the percentages of $(A)$ type I fibres $\left(Y_{1}\right)$ and $(B)$ oxidative (types I and Ila) fibres $\left(Y_{2}\right)(n=8)$.

maximal running and muscle fibre composition; moreover, we noted that a higher percentage of type I and oxidative fibres led to maintenance of higher levels of $\mathrm{oxyHb} / \mathrm{Mb}$ at exhaustion during the maximal running test.

In this regard, we hypothesised that the difference in $\mathrm{O}_{2}$ delivery capacity according to the characteristics of each muscle fibre type might influence the minimum $\mathrm{oxyHb} / \mathrm{Mb}$ levels at exhaustion. In other words, the muscle fibre types were expected to affect the potential to maintain oxyHb/Mb levels during maximal running. Oxidative fibres have greater capillary density as well as greater vascular conductance and $\mathrm{O}_{2}$ delivery. ${ }^{13-16} \mathrm{In}$ fact, Costes et $a l^{17}$ reported that muscle saturation and blood lactate levels during cycling exercise at mild-to-hard intensity improved following the induction of increased capillarisation and oxidative enzyme capacity with 4 weeks of endurance training, suggesting the adaptability of $\mathrm{O}_{2}$ delivery to the $\mathrm{O}_{2}$ demand. Furthermore, muscle $\mathrm{O}_{2}$ saturation has been reported to be significantly lower in healthy older participants; ${ }^{18}$ moreover, in patients with heart failure, $\mathrm{oxyHb} / \mathrm{Mb}$ has 
been demonstrated to be lower, ${ }^{19}$ along with reduced blood flow and limited $\mathrm{O}_{2}$ delivery, ${ }^{20}{ }^{21}$ as compared with younger and normal participants. These results indicate that a decrease in oxyHb/Mb levels is influenced by a restriction in $\mathrm{O}_{2}$ delivery capacity. Therefore, our results -demonstrating that a higher percentage of type I and oxidative fibres was correlated with higher oxyHb/Mb levels at exhaustion during maximal running-provide evidence for previous results. In contrast, glycolytic muscle fibres show lower metabolic efficiency ${ }^{22} 23$ and greater $\mathrm{O}_{2}$ extraction, ${ }^{24}{ }^{25}$ as compared with oxidative fibres. Additionally, the increased recruitment of fast-twitch fibres at high intensity ${ }^{26}{ }^{27}$ has been reported to contribute to decreased $\mathrm{oxyHb} / \mathrm{Mb}$ levels ${ }^{28}$ and decreased muscle oxygenation ${ }^{29}$ accompanied by increased blood lactate concentrations; however, these studies did not involve muscle biopsies. Nioka et $a l^{30}$ reported that the level of $\mathrm{oxyHb} / \mathrm{Mb}$ was lower in the Wingate test than in an aerobic exercise test; although no muscle biopsy was performed, they hypothesised that their results of lowered muscle oxygenation were due to the contribution of organised type IIb muscle fibres. Our results confirm this hypothesis. Furthermore, we noted that, at maximal intensity, muscle fibre composition correlated with $\mathrm{oxyHb} / \mathrm{Mb}$ level; moreover, the relationship was strengthened by the inclusion of type IIa fibres as oxidative fibres, as compared with the inclusion of type I fibres only. This indicated that the recruitment of type IIb fibres occurs at high intensity, ${ }^{31}$ and that the oxyHb/ $\mathrm{Mb}$ level, as evaluated by NIRS, could discriminate the lower blood flow to type IIb fibres. ${ }^{14} 3233$

In this study, the relationship between oxy $\mathrm{Hb} / \mathrm{Mb}$ levels and muscle fibre composition was strong $\left(\mathrm{r}^{2}=0.57-0.89\right)$. The values were sufficient for accurate estimation. Therefore, we consider that muscle fibre composition can be non-invasively estimated from oxy $\mathrm{Hb} / \mathrm{Mb}$ levels during the maximal running test. Previous studies have attempted to assess muscle fibre composition in humans, using non-invasive methods. In these studies, the relaxation time derived from MRI, ${ }^{34}{ }^{35}$ muscle $\mathrm{pH}$ or $\mathrm{PCr} / \mathrm{ATP}, \mathrm{Pi} / \mathrm{ATP},(\mathrm{PCr}+\mathrm{Pi}) / \mathrm{ATP}$ ratio obtained by phosphorus-31 nuclear MR ( $\left.{ }^{31} \mathrm{P}-\mathrm{NMR}\right)$ spectroscopy ${ }^{36} 37$ and carnosine content measured by proton MR spectroscopy $\left({ }^{1} \mathrm{H}-\mathrm{MRS}\right),{ }^{38}$ were correlated to the percentage of type I or type II fibres. However, these methods need an individual with specific expertise and experience, as well as the technology for using these machines, both of which are not easy available. In comparison, the NIRS method is not only non-invasive but also uses a compact device and is inexpensive. Moreover, the estimation accuracy of muscle fibre composition in our method (type I fibres only: 57\%, oxidative fibres: 89\%) was equivalent or higher than those reported in several previous studies $(18-86 \%))^{34-38}$ Therefore, this new, noninvasive method may be useful for accurately estimating muscle fibre composition.

This study has certain limitations. First, we did not investigate differences in the degrees of muscle capillarisation, oxidative enzyme capacity or lactic acidosis according to muscle fibre composition. Therefore, further studies are warranted to determine which specific characteristics of oxidative fibres affect changes in $\mathrm{oxyHb} / \mathrm{Mb}$ levels. Furthermore, the sample size in this study was small $(\mathrm{n}=8)$, although middle-distance runners were selected to provide an adequately long maximal running test and to ensure similar performance levels among the participants. Thus, a future study should investigate the relationship between the oxy $\mathrm{Hb} / \mathrm{Mb}$ level and muscle fibre composition using a larger sample size with a wider distribution range of muscle fibre composition and physiological characteristics.

\section{CONCLUSION}

We conclude that higher oxyHb/Mb levels at exhaustion during maximal running correlated with a higher percentage of oxidative fibres, indicating the potential importance of oxidative fibres in the maintenance of $\mathrm{oxyHb} / \mathrm{Mb}$ levels during maximal running; moreover, muscle fibre composition of the vastus lateralis could be non-invasively estimated from $\mathrm{oxyHb} / \mathrm{Mb}$ levels in this muscle during maximal running.

Competing interests None declared.

\section{Patient consent Obtained.}

Ethics approval The Ethics Committee of Juntendo University.

Provenance and peer review Not commissioned; externally peer reviewed.

Data sharing statement No additional data are available.

Open Access This is an Open Access article distributed in accordance with the Creative Commons Attribution Non Commercial (CC BY-NC 4.0) license, which permits others to distribute, remix, adapt, build upon this work noncommercially, and license their derivative works on different terms, provided the original work is properly cited and the use is non-commercial. See: http:// creativecommons.org/licenses/by-nc/4.0/

\section{REFERENCES}

1. Ferrari M, Mottola L, Quaresima V. Principles, techniques, and limitations of near infrared spectroscopy. Can J Appl Physiol 2004;29:463-87.

2. Hamaoka T, McCully KK, Quaresima V, et al. Near-infrared spectroscopy/imaging for monitoring muscle oxygenation and oxidative metabolism in healthy and diseased humans. J Biomed Opt 2007;12:062105.

3. Belardinelli R, Barstow TJ, Porszasz J, et al. Changes in skeletal muscle oxygenation during incremental exercise measured with near infrared spectroscopy. Eur J Appl Physiol Occup Physiol 1995;70:487-92.

4. Miura T, Takeuchi T, Sato $\mathrm{H}$, et al. Skeletal muscle deoxygenation during exercise assessed by near-infrared spectroscopy and its relation to expired gas analysis parameters. Jpn Circ $J$ 1998;62:649-57.

5. Bhambhani YN. Muscle oxygenation trends during dynamic exercise measured by near infrared spectroscopy. Can J Appl Physiol 2004:29:504-23.

6. Hamaoka T, Mizuno M, Katsumura T, et al. Correlation between indicators determined by near infrared spectroscopy and muscle fiber types in humans. Jpn J Appl Physiol 1998;28:243-8.

7. Ferrari M, Muthalib M, Quaresima V. The use of near-infrared spectroscopy in understanding skeletal muscle physiology: recent developments. Philos Trans A Math Phys Eng Sci 2011;369:4577-90.

8. Delpy DT. Developments in oxygen monitoring. J Biomed Eng 1988;10:533-40. 
9. Chance B, Dait MT, Zhang C, et al. Recovery from exercise-induced desaturation in the quadriceps muscles of elite competitive rowers. Am J Physiol 1992;262:C766-75.

10. McCully KK, Hamaoka T. Near-infrared spectroscopy: what can it tell us about oxygen saturation in skeletal muscle? Exerc Sport Sci Rev 2000;28:123-7.

11. Niwayama M, Lin L, Shao J, et al. Quantitative measurement of muscle hemoglobin oxygenation using near-infrared spectroscopy with correction for the influence of a subcutaneous fat layer. Rev Sci Instr 2000;71:4571-5.

12. Brooke MH, Kaiser KK. Three human myosin ATPase systems and their importance in muscle pathology. Neurology 1970;20:404-5.

13. Andersen P. Capillary density in skeletal muscle of man. Acta Physiol Scand 1975;95:203-5.

14. Mackie BG, Terjung RL. Blood flow to different skeletal muscle fiber types during contraction. Am J Physiol 1983;245:H265-75.

15. Delp MD, Laughlin MH. Regulation of skeletal muscle perfusion during exercise. Acta Physiol Scand 1998;162:411-19.

16. Ahmed SK, Egginton S, Jakeman PM, et al. Is human skeletal muscle capillary supply modelled according to fibre size or fibre type? Exp Physiol 1997;82:231-4.

17. Costes F, Prieur F, Feasson L, et al. Influence of training on NIRS muscle oxygen saturation during submaximal exercise. Med Sci Sports Exerc 2001;33:1484-9.

18. Costes F, Denis C, Roche F, et al. Age-associated alteration of muscle oxygenation measured by near infrared spectroscopy during exercise. Arch Physiol Biochem 1999;107:159-67.

19. Wilson JR, Mancini DM, McCully K, et al. Noninvasive detection of skeletal muscle underperfusion with near-infrared spectroscopy in patients with heart failure. Circulation 1989;80:1668-74.

20. Amery A, Bossaert $\mathrm{H}$, Verstraete $\mathrm{M}$. Muscle blood flow in normal and hypertensive subjects. Influence of age, exercise, and body position. Am Heart J 1969;78:211-16.

21. Wilson JR, Martin JL, Schwartz D, et al. Exercise intolerance in patients with chronic heart failure: role of impaired nutritive flow to skeletal muscle. Circulation 1984;69:1079-87.

22. Crow MT, Kushmerick MJ. Chemical energetics of slow- and fast-twitch muscles of the mouse. J Gen Physiol 1982;79:147-66.

23. Borrani $F$, Candau R, Millet GY, et al. Is the VO2 slow component dependent on progressive recruitment of fast-twitch fibers in trained runners? J Appl Physiol 2001;90:2212-20.
24. Behnke BJ, McDonough P, Padilla DJ, et al. Oxygen exchange profile in rat muscles of contrasting fibre types. $J$ Physiol (Lond) 2003;549(Pt 2):597-605.

25. McDonough P, Behnke BJ, Padilla DJ, et al. Control of microvascular oxygen pressures in rat muscles comprised of different fibre types. J Physiol (Lond) 2005;563:903-13.

26. Hannerz J. Discharge properties of motor units in relation to recruitment order in voluntary contraction. Acta Physiol Scand 1974;91:374-85.

27. Skinner JS, McLellan TM. The transition from aerobic to anaerobic metabolism. Res Q Exerc Sport 1980;51:234-48.

28. Miura $\mathrm{H}$, Araki $\mathrm{H}$, Matoba $\mathrm{H}$, et al. Relationship among oxygenation, myoelectric activity, and lactic acid accumulation in vastus lateralis muscle during exercise with constant work rate. Int J Sports Med 2000;21:180-4.

29. Ding H, Wang G, Lei W, et al. Non-invasive quantitative assessment of oxidative metabolism in quadriceps muscles by near infrared spectroscopy. Br J Sports Med 2001;35:441-4.

30. Nioka S, Moser D, Lech G, et al. Muscle deoxygenation in aerobic and anaerobic exercise. Adv Exp Med Biol 1998;454:63-70.

31. Sale DG. Influence of exercise and training on motor unit activation. Exerc Sport Sci Rev 1987;15:95-151.

32. Armstrong RB, Laughlin $\mathrm{MH}$. Rat muscle blood flows during high-speed locomotion. J Appl Physiol 1985;59:1322-8.

33. Laughlin $\mathrm{MH}$, Armstrong RB. Muscle blood flow during locomotory exercise. Exerc Sport Sci Rev 1985;13:95-136.

34. Kuno S, Katsuta T, Inouye I, et al. Relationship between MR relaxation time and muscle fiber composition. Radiology 1988:169:567-8.

35. Houmard JA, Smith R, Jendrasiak GL. Relationship between MRI relaxation time and muscle fiber composition. $J$ Appl Physiol 1995;78:807-9.

36. Mizuno M, Secher NH, Quistorff B. 31P-NMR spectroscopy, rsEMG, and histochemical fiber types of human wrist flexor muscles. $J$ Appl Physiol 1994;76:531-8.

37. Takahashi H, Kuno SY, Katsuta S, et al. Relationships between fiber composition and NMR measurements in human skeletal muscle. NMR Biomed 1996;9:8-12.

38. Baguet A, Everaert I, Hespel P, et al. A new method for non-invasive estimation of human muscle fiber type composition. PLOS ONE 2011;6:e21956 